\title{
Full-Wave Analysis of Ultrahigh Electromechanical Coupling Surface Acoustic Wave Propagating Properties in a Relaxor Based Ferroelectric Single Crystal/Cubic Silicon Carbide Layered Structure
}

\author{
Xiaojun Ji, Qiang Xiao, and Jing Chen \\ Department of Electronic Information and Electrical Engineering, Shanghai Jiao Tong University, Shanghai 200240, China \\ Correspondence should be addressed to Jing Chen; jingchen0408@sjtu.edu.cn
}

Received 15 May 2017; Accepted 17 September 2017; Published 16 October 2017

Academic Editor: Zhiping Qiu

Copyright (C) 2017 Xiaojun Ji et al. This is an open access article distributed under the Creative Commons Attribution License, which permits unrestricted use, distribution, and reproduction in any medium, provided the original work is properly cited.

This paper describes a full-wave analysis of ultrahigh electromechanical coupling surface acoustic wave (SAW) of Y-cut X propagating $\mathrm{Pb}\left(\mathrm{In}_{1 / 2} \mathrm{Nb}_{1 / 2}\right) \mathrm{O}_{3}-\mathrm{Pb}\left(\mathrm{Mg}_{1 / 3} \mathrm{Nb}_{2 / 3}\right) \mathrm{O}_{3}-\mathrm{PbTiO}_{3}$ (YX-PIMNT) single crystals on a cubic silicon carbide (3C-SiC) substrate. There are several eigenmodes including shear horizontal ( $\mathrm{SH}$ ) and Rayleigh SAWs. Based on the finite-element method (FEM), the phase velocity $\left(v_{p}\right)$ and coupling factor $\left(K^{2}\right)$ of SAWs varying with the top electrode thickness, thickness, and Euler angle $(\theta)$ of the YX-PIMNT substrate have been investigated. $K^{2}$ of SH SAW can reach an extremely high value of $75.9 \%$. The proper control of structural parameters can suppress unwanted responses caused by other modes without deteriorating the coupling factor. The large $K^{2}$ value of SH SAW and suppression of unwanted responses have highly promising applications in developing ultrawideband and tunable SAW filters. Finally, the performance of $3 \mathrm{C}-\mathrm{SiC}$ and $6 \mathrm{H}-\mathrm{SiC}$ as substrates was investigated, and $3 \mathrm{C}-\mathrm{SiC}$ was identified as a more attractive substrate candidate than $6 \mathrm{H}-\mathrm{SiC}$.

\section{Introduction}

Surface acoustic wave (SAW) devices are widely used in mobile phones and various modern consumer telecommunication systems [1]. A high electromechanical coupling factor is suitable for the design of ultrawideband SAW filters [2-4]. Relaxor based ferroelectric single crystals, such as $\mathrm{Pb}\left(\mathrm{Mg}_{1 / 3} \mathrm{Nb}_{2 / 3}\right) \mathrm{O}_{3}-x \mathrm{PbTiO}_{3}$ (PMNT or PMN- $x \mathrm{PT}$ ) and $\mathrm{Pb}\left(\mathrm{Zn}_{1 / 3} \mathrm{Nb}_{2 / 3}\right) \mathrm{O}_{3}-x \mathrm{PbTiO}_{3}$ (PZNT or PZN- $x \mathrm{PT}$ ), have ultrahigh electromechanical coupling factor $k_{33}(>94 \%)$ and piezoelectric constant $d_{33}(>2500 \mathrm{pC} / \mathrm{N})$ near the morphotropic phase boundary at room temperature [5-9]. However, PMNT single crystals have low Curie temperature $\left(T_{c} \approx\right.$ $\left.130^{\circ} \mathrm{C}\right)$ and phase transition temperature $\left(T_{\mathrm{rT}} \approx 85^{\circ} \mathrm{C}\right)$; these characteristics limit their applications under high temperatures. Recently, a ternary compound $\mathrm{Pb}\left(\mathrm{In}_{1 / 2} \mathrm{Nb}_{1 / 2}\right) \mathrm{O}_{3}$ $\mathrm{Pb}\left(\mathrm{Mg}_{1 / 3} \mathrm{Nb}_{2 / 3}\right) \mathrm{O}_{3}-\mathrm{PbTiO}_{3}$ (PIMNT or PIN-PMN- $x \mathrm{PT}$ ) has attracted considerable attention given its high $T_{\mathrm{c}}\left(\approx 200^{\circ} \mathrm{C}\right)$ and $T_{\mathrm{rT}}\left(\approx 110^{\circ} \mathrm{C}\right)[10,11]$. Ji and Chen previously investigated
SAW propagation on a YX-PIN-PMN-PT substrate and achieved a large $K^{2}$ of shear horizontal (SH) SAW $(\approx 70 \%)$ on a diamond substrate [12-14].

$3 \mathrm{C}-\mathrm{SiC}$ is an attractive candidate substrate given its high velocity and $K^{2}[15,16]$. This paper reports a full-wave analysis of YX-PIMNT/3C-SiC substrate conducted via the finite-element method (FEM) with the commercial software package COMSOL Multiphysics. The variation in the phase velocity $\left(v_{p}\right)$ and coupling factor $\left(K^{2}\right)$ of SAWs with the top electrode thickness, thickness, and Euler angle $(\theta)$ of the YX-PIMNT substrate was investigated. Results showed that $K^{2}$ of SH SAW can reach a maximum value of $75.9 \%$ in this configuration. By properly controlling structural parameters, unwanted responses caused by other modes can be suppressed without deteriorating the coupling factor. The large $K^{2}$ value of SH SAW and suppression of unwanted responses extremely have highly promising applications in developing ultrawideband and tunable SAW filters. Finally, The performance of $3 \mathrm{C}-\mathrm{SiC}$ and $6 \mathrm{H}-\mathrm{SiC}$ as substrates was 


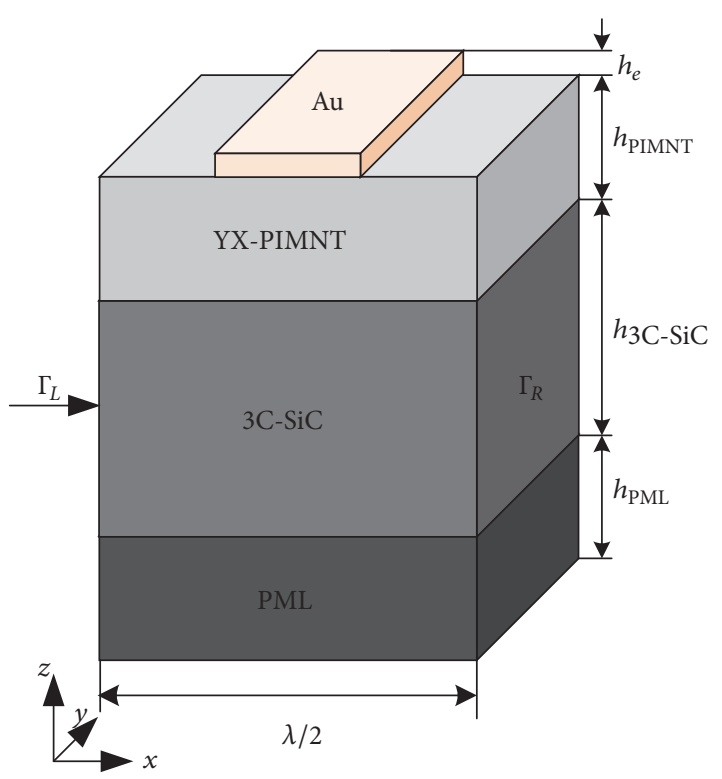

FIGURE 1: Quasi-3D periodic FEM model used in the simulation (not to scale).

investigated, and $3 \mathrm{C}-\mathrm{SiC}$ was found to be a more attractive substrate candidate than $6 \mathrm{H}-\mathrm{SiC}$.

\section{Modeling and Simulation}

Figure 1 shows the modeled structure of an electrode layer/YX-PIMNT/3C-SiC substrate configuration. The thickness of each layer was denoted as $h_{e}, h_{\mathrm{PIMNT}}$, and $h_{3 \mathrm{C}-\mathrm{SiC}}$. In the model, the wavelength $(\lambda)$ was set to $2 \mu \mathrm{m}$. Only a half period was considered, and the antisymmetric periodic boundary condition was applied to the field variables at the left $\left(\Gamma_{L}\right)$ and right surfaces $\left(\Gamma_{R}\right)$. The perfectly matched layer was applied to the bottom to decrease model size and suppress the spurious resonances caused by the reflection at the bottom. In this study, we assumed that waves propagate along $x$-direction; then, waves that propagate along other directions could be ignored. Thus, the periodic boundary condition was applied to the variables between the $+y$ and $-y$ surfaces.

A $3 \mathrm{D}$ periodical model of the layered structure was established in the commercial software package COMSOL Multiphysics. Au was chosen as the interdigital transducer (IDT) electrode material. The material constants of YXPIMNT and 3C-SiC crystal were obtained from [17-19].

Harmonic analysis was conducted with $1 \mathrm{~V}$ loaded to the electrode. Figure 2 presents an image of the calculated acoustic wave radiation. It is shown that $\mathrm{SH}$ and Rayleigh SAWs mainly concentrate their energy near the metal electrode, whereas bulk waves radiate their energy to the interior of the model.

Figure 3 shows the calculated relative admittance in decibels, namely, $20 \lg |Y(f)|$ of infinitely long IDTs on the layered structure as a function of frequency when $h_{\mathrm{PIMNT}}=$ $0.3 \lambda$. Five eigenmodes were observed, and the frequency ranged from $0.3 \mathrm{GHz}$ to $3 \mathrm{GHz}$. The first eigenmode with

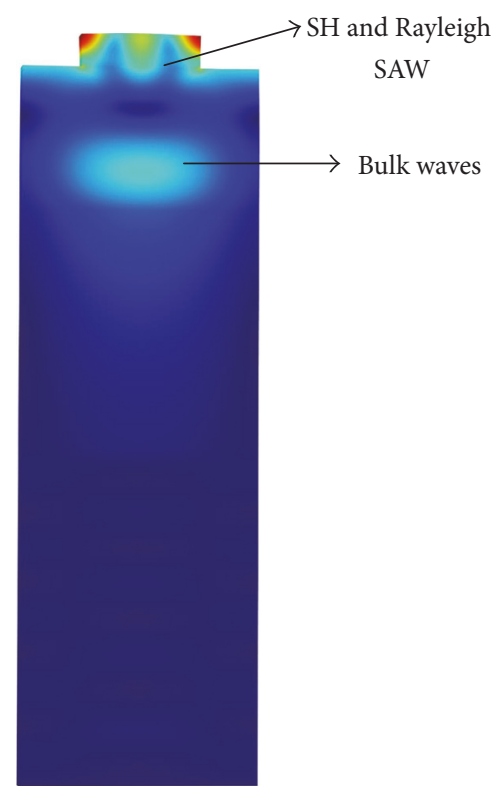

FIGURE 2: Image of the calculated acoustic wave radiation.

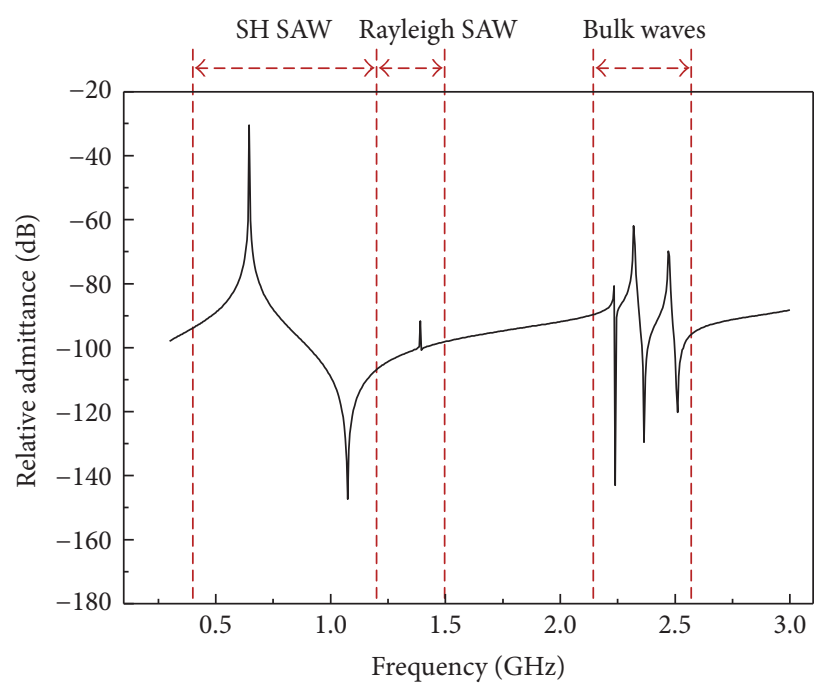

FIGURE 3: Calculated relative admittance $Y(f)$ of infinitely long IDTs on layered structure as a function of frequency when $h_{\mathrm{PIMNT}}=0.3 \lambda$.

$f_{r} \approx 650 \mathrm{MHz}$ is the main mode that corresponds to $\mathrm{SH}$ SAW. The second eigenmode is associated with the traditional Rayleigh SAW. Higher order eigenmodes are also observed and identified as bulk waves as shown in Figure 3.

Figures 4(a) and 4(b) show the normalized displacement field distribution for SH and Rayleigh SAWs on the layered structure. The dominant displacement components of SH and Rayleigh SAWs are SH and SV, respectively. The peak value of displacement is located in the electrode layer and decays exponentially in the interlayer of YX-PIMNT and 3C-SiC. This finding indicates that the vibration energy is mainly concentrated in the electrode and the YX-PIMNT thin layer, and only limited energy penetrates the $3 \mathrm{C}-\mathrm{SiC}$ layer. 


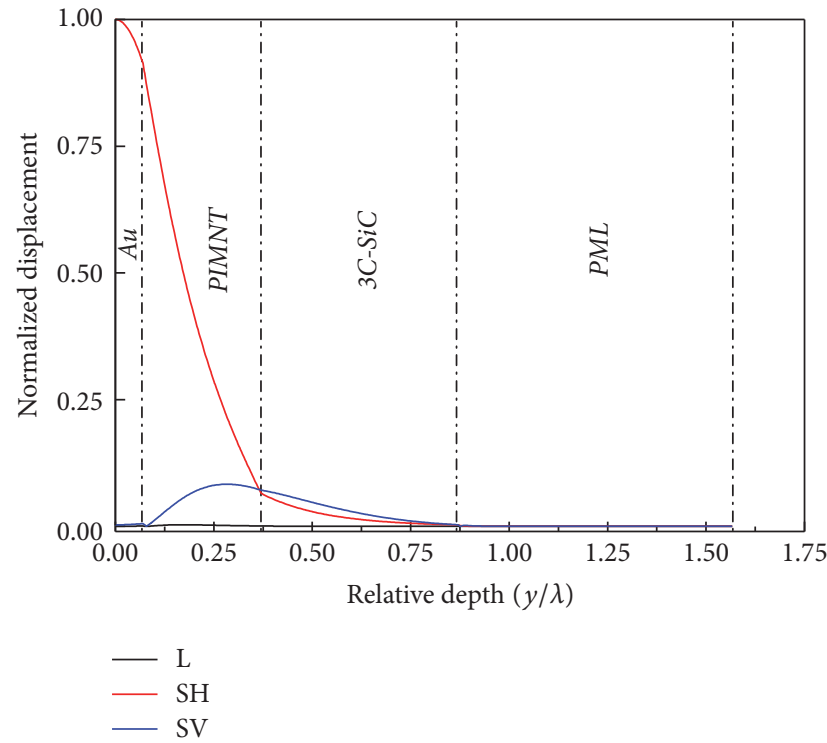

(a)

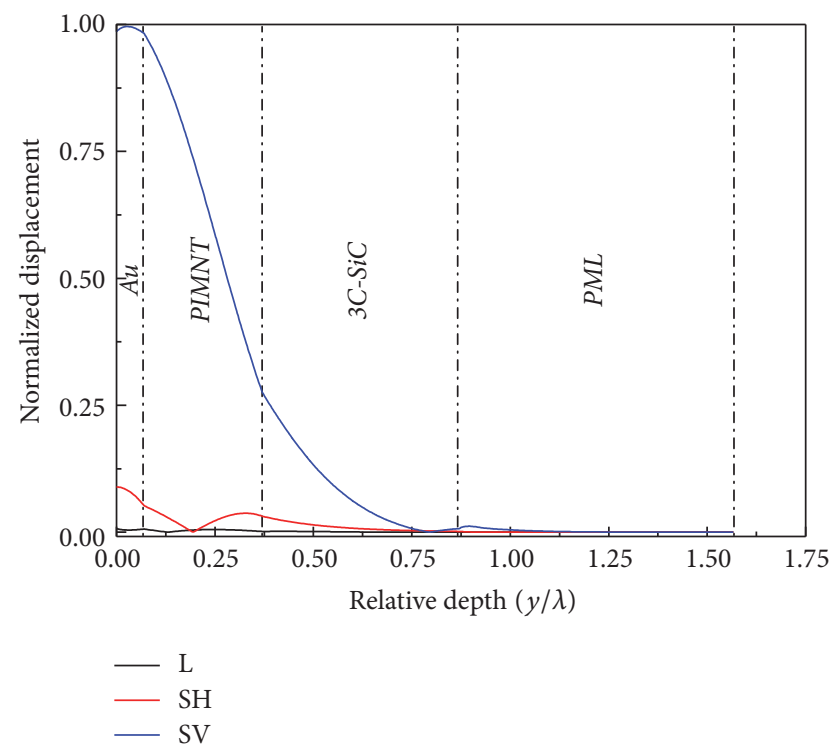

(b)

FIGURE 4: Normalized displacement field distribution for SH and Rayleigh SAWs on the layered structure: (a) SH SAW and (b) Rayleigh SAW.

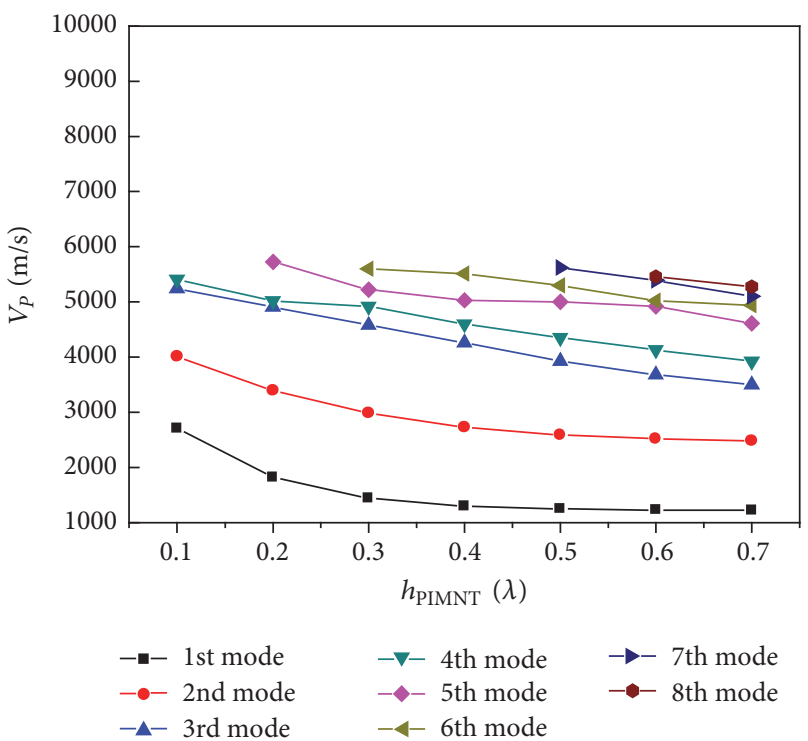

(a)

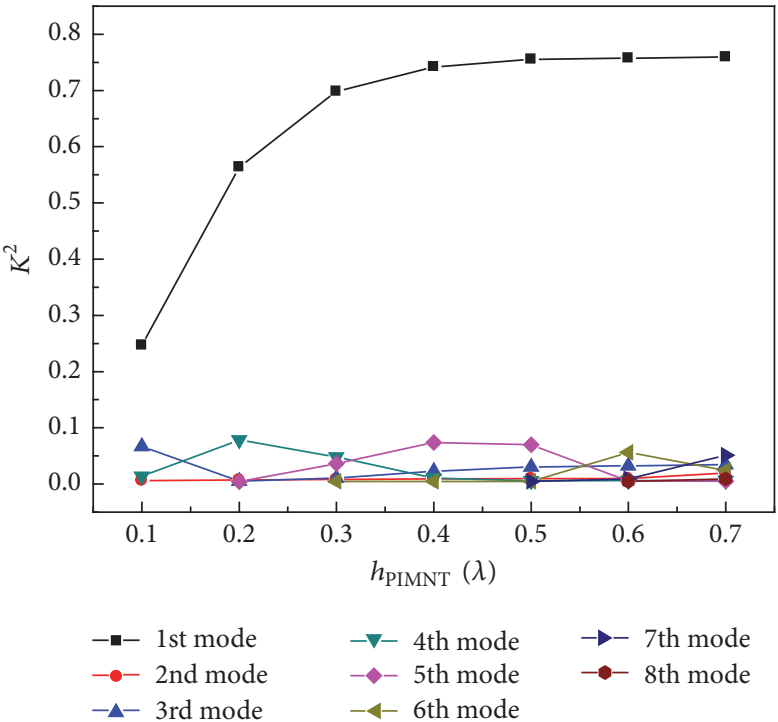

(b)

Figure 5: Dispersion curves of phase velocity (a) and $K^{2}(\mathrm{~b})$ as a function of $h_{\text {PIMNT }}$.

\section{Results and Discussion}

The $f_{r}$ and $f_{a}$ values for each eigenmode can be obtained when the relative admittance reaches peaks and troughs, respectively. $K^{2}$ is the electroacoustic energy conversion efficiency of a resonator, which can be estimated using the following formula derived from the equivalent circuit analysis [20]:

$$
K^{2}=\frac{\pi f_{r} / 2 f_{a}}{\tan \left(\pi f_{r} / 2 f_{a}\right)}
$$

Hence, a large distance between $f_{r}$ and $f_{a}$ indicates a large $K^{2} . K^{2}$ of SH SAW is $68.5 \%$, whereas that of other eigenmodes is approximately zero for $h_{\text {PIMNT }}=0.3 \lambda$. This finding indicates that unwanted responses can be suppressed by choosing a proper thickness of YX-PIMNT, which is extremely attractive in developing wideband and tunable SAW filters.

The dispersion curves of phase velocity and $K^{2}$ as a function of YX-PIMNT thickness were estimated with the calculated admittance and illustrated in Figures 5(a) and 5(b), respectively. The number of eigenmodes increases from 4 to 


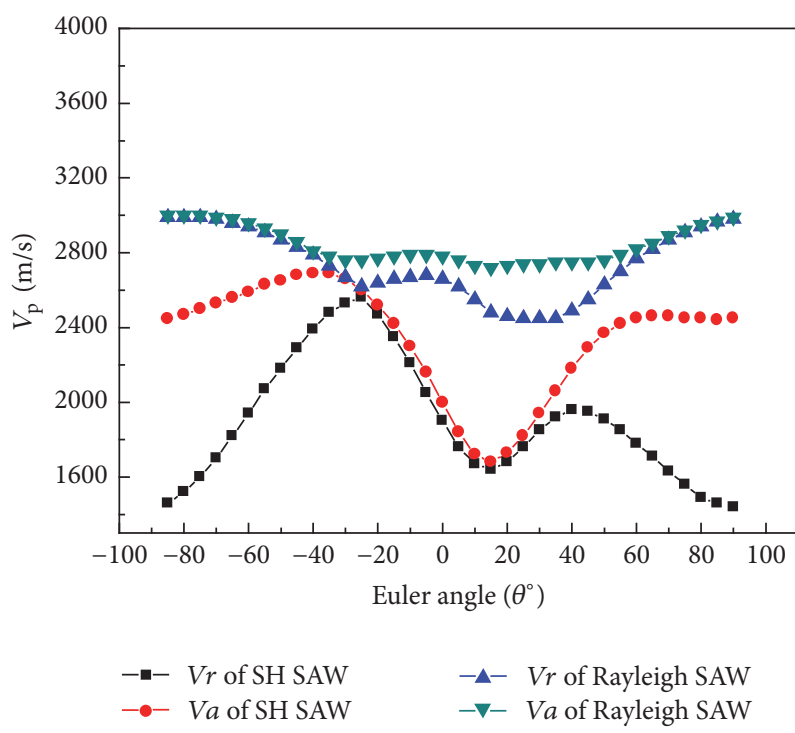

(a)

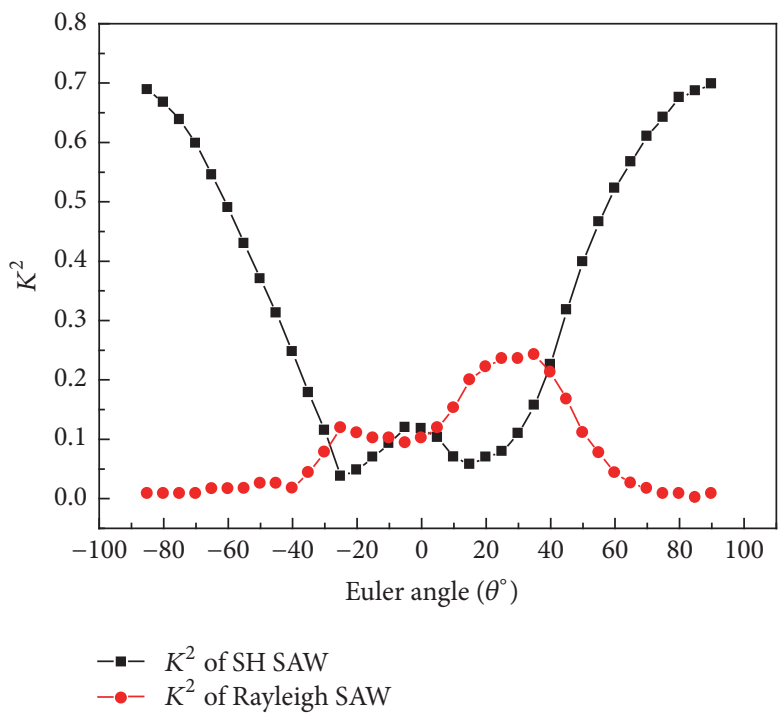

(b)

Figure 6: (a) Effective velocities and (b) estimated $K^{2}$ (as a function of $\theta$ from $-90^{\circ}$ to $90^{\circ}$ ) of $\mathrm{SH}$ and Rayleigh SAWs.

8 when $h_{\text {PIMNT }}$ ranges from $0.1 \lambda$ to $0.7 \lambda$. When $h_{\mathrm{PIMNT}}=$ $0.3 \lambda$, the maximum $K^{2}$ value of the higher modes is $4.8 \%$, indicating that these modes have little energy. A fairly large SH SAW $K^{2}$ of $69.1 \%$ and a high SH SAW phase velocity of $1440 \mathrm{~m} / \mathrm{s}$ are simultaneously achieved.

Figures 6(a) and 6(b) show the variation in the calculated effective velocities and $K^{2}$ of the SH and Rayleigh SAWs with Euler angle $\theta$ ranging from $-90^{\circ}$ to $90^{\circ}$. The effective velocities are defined by $v_{r}=f_{r} \lambda$ and $v_{a}=f_{a} \lambda$ at the resonance and antiresonance frequencies, respectively. $v_{r}$ of the SH SAW gradually increases and reaches a value similar to that of the Rayleigh SAW, which is over $2600 \mathrm{~m} / \mathrm{s}$. The Rayleigh SAW exists within a wide range of Euler angles from $-65^{\circ}$ to $70^{\circ}$. A pure SH SAW is achieved only when $\theta$ is in the ranges of $-90^{\circ}$ to $-70^{\circ}$ and $75^{\circ}$ to $90^{\circ}$. Different $K^{2}$ values from $59.7 \%$ to $68.9 \%$ are obtained for SH SAW, whereas those for Rayleigh SAW are approximately zero, which is beneficial for designing SAW filters with different bandwidth. $K^{2}$ of the Rayleigh SAW gradually increases from $\theta=-65^{\circ}$, reaches the largest value of $24.2 \%$ when $\theta=35^{\circ}$, and decreases to zero when $\theta=75^{\circ}$.

The effects of mass loading on the electrode layer should not be neglected because the thickness of the electrode layer is comparable with that of the thinned YX-PIMNT substrate. Therefore, the dependence of the $K^{2}$ of the $\mathrm{SH}$ and Rayleigh SAWs on the thickness of the Au electrode was investigated and is shown in Figure 7. In this case, $h_{\text {PIMNT }}=0.3 \lambda$ and Euler angle $\theta=90^{\circ}$; thus, unwanted waves are sufficiently suppressed. $K^{2}$ of the SH SAW ranges from $62.4 \%$ to $69.8 \%$, whereas that of Rayleigh SAW is approximately zero. When $h_{e}=0.05 \lambda, K^{2}$ of the SH SAW reaches a maximum value of $69.8 \%$.

The performance of different types of silicon carbide as substrates was studied. Mirgorodsky et al. [21] reported that $2 \mathrm{H}, 4 \mathrm{H}$, and $6 \mathrm{H}$ silicon carbide have exactly similar elastic

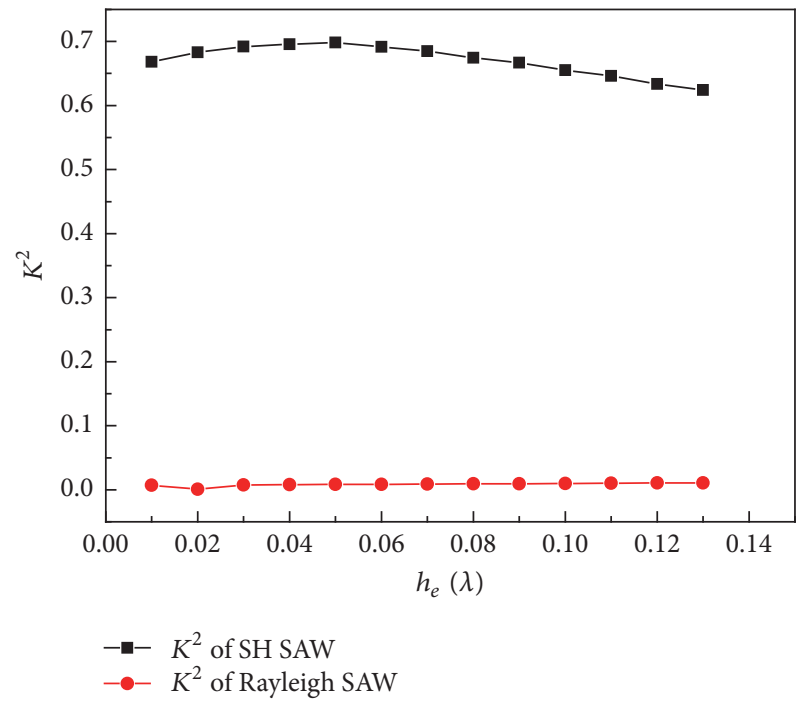

FIGURE 7: Estimated $K^{2}$ values (as a function of $h_{e}$ ) of the SH and Rayleigh SAWs.

and piezoelectric properties. Thus, $3 \mathrm{C}-\mathrm{SiC}$ and $6 \mathrm{H}-\mathrm{SiC}$ were examined.

Figure 8 presents the simulation results of the $K^{2}$ curves as a function of electrode thickness for $\mathrm{SH}$ and Rayleigh SAWs that propagate along the YX-PIMNT/3C-SiC and YXPIMNT/6H-SiC substrates. The $h_{\text {PIMNT }}$ was fixed at $0.3 \lambda$ and the Euler angle at $90^{\circ} . K^{2}$ of SH SAW in the YX-PIMNT/3C$\mathrm{SiC}$ substrate is considerably higher than its value in the YXPIMNT/6H-SiC substrate, whereas the Rayleigh SAW has low $K^{2}$ values in both substrates. Hence, $3 \mathrm{C}$-SiC is a more attractive candidate as the substrate in this model than $6 \mathrm{H}$ $\mathrm{SiC}$. 


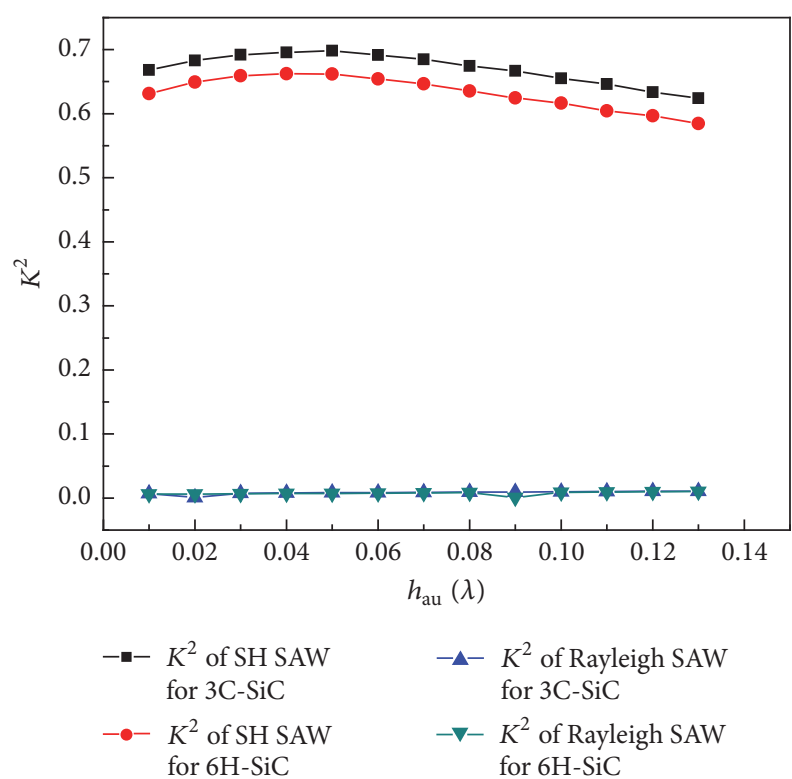

FIgURE 8: Comparison of $K^{2}$ for $\mathrm{SH}$ and Rayleigh SAWs on YX-PIMNT/3C-SiC with YX-PIMNT/6H-SiC layered structure for various electrode thicknesses with $h_{\mathrm{PIMNT}}=0.3 \lambda$ and $\theta=90^{\circ}$.

However, the material losses were not taken into account in this work. These losses can be simulated in such model by giving an imaginary part to the elastic, piezoelectric, and dielectric constants to consider the mechanical, coupling, and dielectric losses; then, we can calculate the $Q$ factors. Currently, we have not yet added these losses mainly due to the lack of a full complex matrix for reference. In the following work we will consider testing these parameters with the material suppliers for accurate simulation of material losses and $Q$ factors.

\section{Conclusion}

This study presents a full-wave analysis of ultrahigh electromechanical coupling SAW of YX-PIMNT on 3C-SiC substrate. There are several eigenmodes including $\mathrm{SH}$ and Rayleigh SAWs. FEM results show that $v_{p}$ and $K^{2}$ of SAWs vary with the top electrode thickness, thickness, and Euler angle of the YX-PIMNT substrate.

Results show that $K^{2}$ of SH SAW can reach an extremely high value of $75.9 \%$. Unwanted responses caused by other modes can be suppressed by properly controlling structural parameters without deteriorating the coupling factor. A relatively pure SH SAW is obtained when the thickness of YX-PIMNT is $0.3 \lambda$ and $\theta$ has a wide range of $-90^{\circ}$ to $-70^{\circ}$ and $75^{\circ}$ to $90^{\circ}$. The largest $K^{2}$ achieved for the pure SH SAW is approximately $69.8 \%$ when the thickness of electrode is $0.05 \lambda$ and $\theta$ is $90^{\circ}$. This extremely large $K^{2}$ value of SH SAW and suppression of unwanted responses have an extremely promising application in developing ultrawideband and tunable SAW filters. Finally, the performance of $3 \mathrm{C}-\mathrm{SiC}$ and $6 \mathrm{H}-$ $\mathrm{SiC}$ as a substrate was investigated, and $3 \mathrm{C}-\mathrm{SiC}$ is found to be a more attractive substrate candidate than $6 \mathrm{H}-\mathrm{SiC}$.

\section{Conflicts of Interest}

The authors declare that there are no conflicts of interest regarding the publication of this paper. They confirm that the mentioned funding in the Acknowledgments does not lead to any conflicts of interest regarding the publication of this manuscript.

\section{Acknowledgments}

This research was supported by the Natural Science Foundation of Shanghai under Grant no. 14ZR1422000 and the National Natural Science Foundation of China (NSFC) under Grant nos. 11404209 and 51475306.

\section{References}

[1] Y. Wang, K.-Y. Hashimoto, T. Omori, and M. Yamaguchi, "A full-wave analysis of surface acoustic waves propagating on a $\mathrm{SiO} 2$ overlay/metal grating/rotated Y-cut X-propagating LiNbO3 substrate structure," Japanese Journal of Applied Physics, vol. 48, no. 7, Article ID 07GG06, 2009.

[2] J. Chen, Q. Zhang, T. Han et al., “Theoretical analysis of surface acoustic wave propagating properties of Y-cut nano lithium niobate film on silicon dioxide," AIP Advances, vol. 5, no. 8, Article ID 087173, 2015.

[3] T. Komatsu, K.-Y. Hashimoto, T. Omori, and M. Yamaguchi, "Tunable radio-frequency filters using acoustic wave resonators and variable capacitors," Japanese Journal of Applied Physics, vol. 49, no. 7, Article ID 07HD24, 2010.

[4] M. Kadota, T. Kimura, and Y. Ida, "Tunable filters using ultrawide-band surface acoustic wave resonator composed of grooved $\mathrm{Cu}$ electrode on LiNbO3," Japanese Journal of Applied Physics, vol. 49, no. 7, Article ID 07HD26, 2010.

[5] S.-E. Park and T. R. Shrout, "Ultrahigh strain and piezoelectric behavior in relaxor based ferroelectric single crystals," Journal of Applied Physics, vol. 82, no. 4, pp. 1804-1811, 1997.

[6] R. F. Service, "Shape-changing crystals get shiftier," Science, vol. 275, no. 5308, p. 1878, 1997.

[7] H. Luo, G. Xu, H. Xu, P. Wang, and Z. Yin, "Compositional homogeneity and electrical properties of lead magnesium niobate titanate single crystals grown by a modified bridgman technique," Japanese Journal of Applied Physics, vol. 39, no. 9, pp. 5581-5585, 2000.

[8] Q. Zhou, K. H. Lam, H. Zheng, W. Qiu, and K. K. Shung, "Piezoelectric single crystal ultrasonic transducers for biomedical applications," Progress in Materials Science, vol. 66, pp. 87111, 2014.

[9] E. Sun and W. Cao, "Relaxor-based ferroelectric single crystals: growth, domain engineering, characterization and applications," Progress in Materials Science, vol. 65, pp. 124-210, 2014.

[10] G. Xu, K. Chen, D. Yang, and J. Li, "Growth and electrical properties of large size $\mathrm{Pb}(\mathrm{In} 1 / 2 \mathrm{Nb} 1 / 2) \mathrm{O}-3-\mathrm{Pb}(\mathrm{Mg} 1 / 3 \mathrm{Nb} 2 / 3) \mathrm{O}-3$ $\mathrm{PbTiO} 3$ crystals prepared by the vertical Bridgman technique," Applied Physics Letters, vol. 90, no. 3, Article ID 032901, 2007.

[11] S. Zhang, F. Li, N. P. Sherlock et al., "Recent developments on high Curie temperature PINPMNPT ferroelectric crystals," Journal of Crystal Growth, vol. 318, no. 1, pp. 846-850, 2011.

[12] J. Chen, J. Liu, K.-Y. Hashimoto et al., "Ultra-wideband surface acoustic wave resonator employing $\mathrm{Pb}(\mathrm{In} 1 / 2 \mathrm{Nb} 1 / 2) \mathrm{O}-3$ $\mathrm{Pb}(\mathrm{Mg} 1 / 3 \mathrm{Nb} 2 / 3) \mathrm{O}-3-\mathrm{PbTiO} 3$ crystals," Applied Physics Letters, vol. 100, no. 2, Article ID 022903, 2012. 
[13] J. Chen, H. Wang, K.-Y. Hashimoto et al., "Theoretical analysis of ultrahigh electromechanical coupling surface acoustic wave propagation in $\mathrm{Pb}(\mathrm{In} 1 / 2 \mathrm{Nb} 1 / 2) \mathrm{O}-3-\mathrm{Pb}(\mathrm{Mg} 1 / 3 \mathrm{Nb} 2 / 3) \mathrm{O}-3$ PbTiO3 crystals," Journal of Applied Physics, vol. 109, no. 5, Article ID 054104, 2011.

[14] X. Ji, J. Chen, T. Han, L. Zhou, Q. Zhang, and G. Tang, "Enlarged phase velocities of ultra-wideband surface acoustic wave devices with relaxor based ferroelectric single crystal/diamond layered structure," Diamond and Related Materials, vol. 66, pp. 213-216, 2016.

[15] Q. Z. Zhang, T. Han, G. B. Tang et al., "SAW characteristics of AlN/SiO2/3C-SiC layered structure with embedded electrodes," IEEE Transactions on Ultrasonics, Ferroelectrics, and Frequency Control, vol. 63, no. 10, pp. 1608-1612, 2016.

[16] C.-M. Lin, Y.-Y. Chen, V. V. Felmetsger et al., "Surface acoustic wave devices on AlN/3C-SiC/Si multilayer structures," Journal of Micromechanics and Microengineering, vol. 23, no. 2, Article ID 025019, 2013.

[17] V. Cimalla, J. Pezoldt, and O. Ambacher, "Group III nitride and SiC based MEMS and NEMS: Materials properties, technology and applications," Journal of Physics D: Applied Physics, vol. 40, no. 20, pp. 6386-6434, 2007.

[18] K. Karch, P. Pavone, W. Windl, O. Schütt, and D. Strauch, "Ab initio calculation of structural and lattice-dynamical properties of silicon carbide," Physical Review B: Condensed Matter and Materials Physics, vol. 50, no. 23, pp. 17054-17063, 1994.

[19] X. Z. Liu, S. J. Zhang, J. Luo et al., "A complete set of material properties of single domain $0.26 \mathrm{~Pb}(\mathrm{In} 1 / 2 \mathrm{Nb} 1 / 2) \mathrm{O}-3$ $0.46 \mathrm{~Pb}(\mathrm{Mg} 1 / 3 \mathrm{Nb} 2 / 3) \mathrm{O}-3-0.28 \mathrm{PbTiO}(3)$ single crystals (vol 96, 012907, 2010)," Applied Physics Letters, vol. 97, no. 1, 2010.

[20] K. Hashimoto, H. Asano, T. Omori, and M. Yamaguchi, "Ultrawideband surface acoustic wave devices using Cu-grating/ rotated-YX-LiNBO3-substrate structure," Japanese Journal of Applied Physics, vol. 43, no. 5, pp. 3063-3066, 2004.

[21] A. P. Mirgorodsky, M. B. Smirnov, E. Abdelmounîm, T. Merle, and P. E. Quintard, "Molecular approach to the modeling of elasticity and piezoelectricity of SiC polytypes," Physical Review B: Condensed Matter and Materials Physics, vol. 52, no. 6, pp. 3993-4000, 1995. 


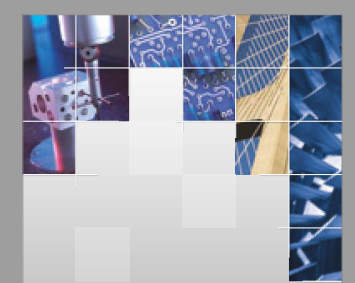

\section{Enfincering}
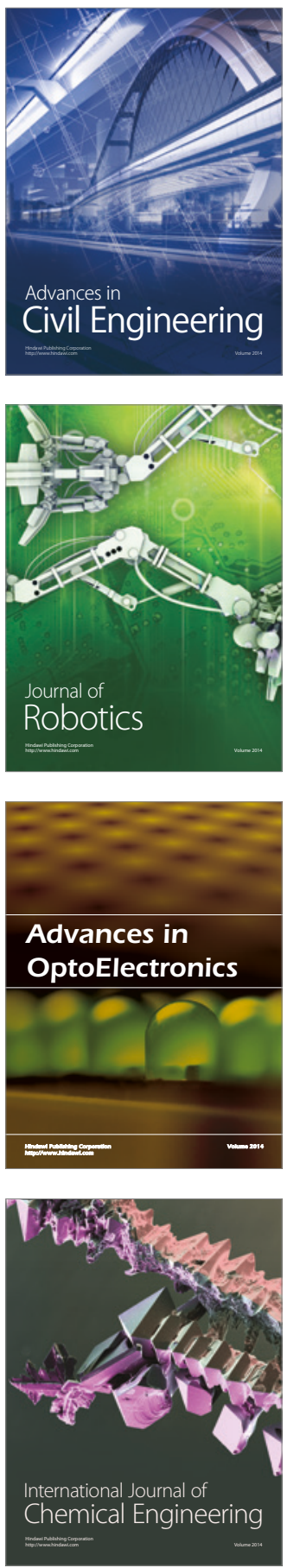

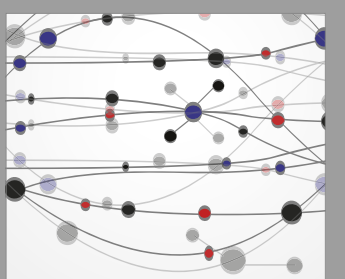

The Scientific World Journal

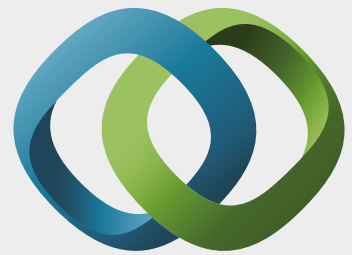

\section{Hindawi}

Submit your manuscripts at

https://www.hindawi.com
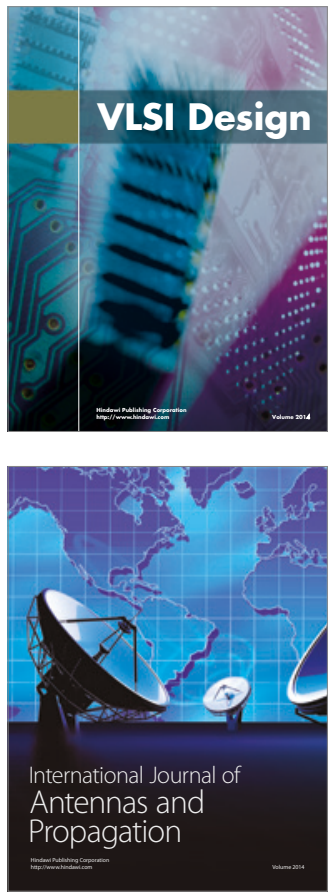

\section{Rotating}

Machinery
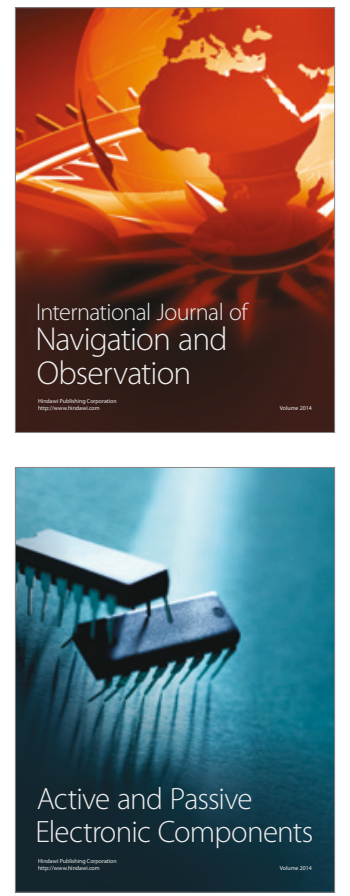
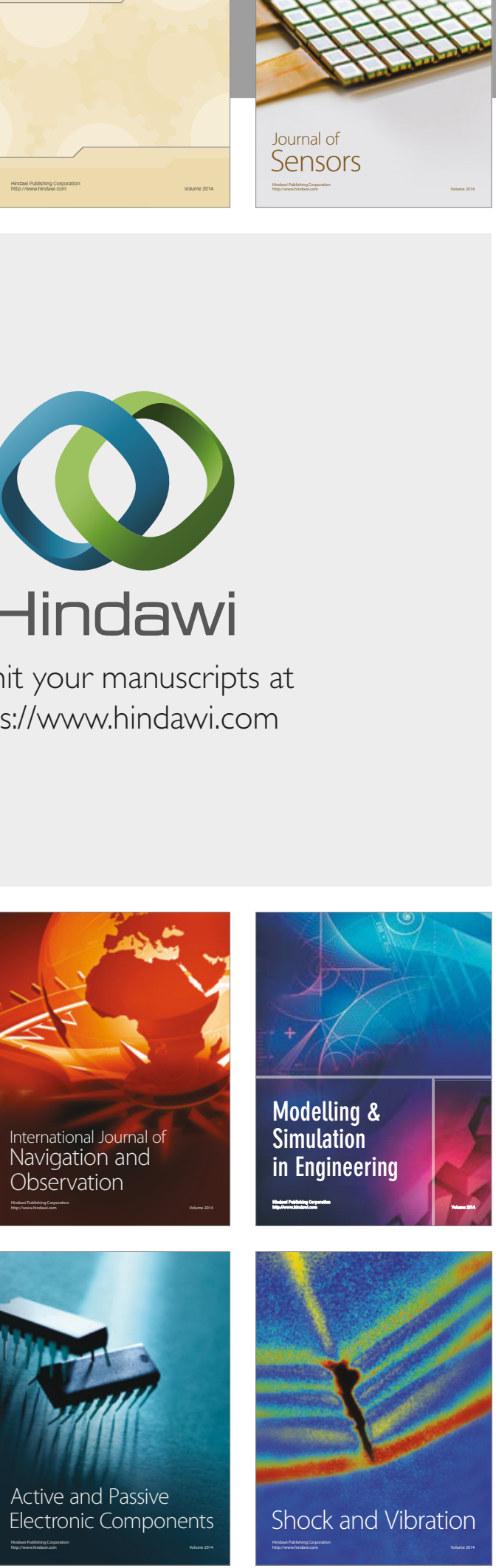
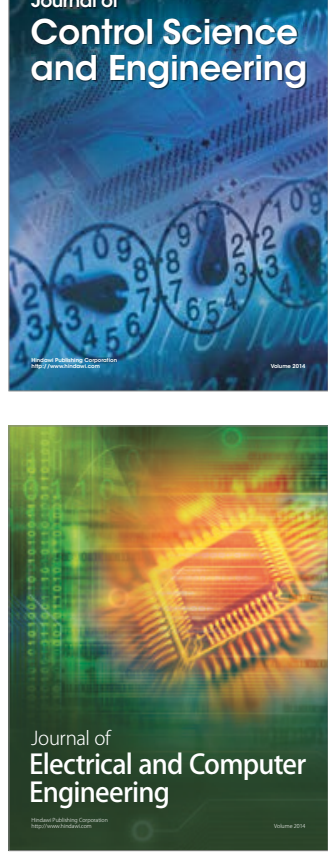

Distributed

Journal of

Control Science

and Engineering
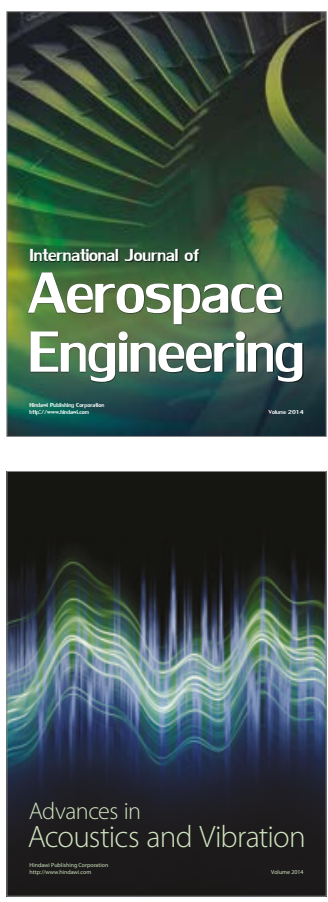

Sensor Networks 